Int. J. Electrochem. Sci., 15 (2020) $868-878$

International Journal of

ELECTROCHEMICAL

SCIENCE

$\underline{\text { www.electrochemsci.org }}$

\title{
Cathodic Protection Criteria for X80 Steel in Soil Extract
}

\author{
Shixiong $\mathrm{Wu}^{1}$, Zhiming $\mathrm{Gao}^{1, *}$, Jun Zhao ${ }^{2}$, Liqin Wang ${ }^{3}$, Yingjie Liu ${ }^{1}$, Meijun Wu ${ }^{1}$,Wenbin $\mathrm{Hu}^{1}$ \\ ${ }^{1}$ School of Material Science and Technology, Tianjin University, Tianjin, 30072, China \\ Engineering Research Center of Composite and Functional Materials, Ministry of Education, Tianjin, \\ 30350, China \\ ${ }^{2}$ Petrochina pipeline company oil\&gas storage and transportation technology sub-company, Langfang, \\ 065000, China \\ ${ }^{3}$ Amperex Technology Limited, Ningde, 352100, China \\ *E-mail: gaozhiming@tju.edu.cn
}

doi: $10.20964 / 2020.01 .52$

Received: 25 August 2019 / Accepted: 30 October 2019 / Published: 30 November 2019

Potentiodynamic polarization, electrochemical impedance spectroscopy and slow strain tensile rate tests were used to establish the negative critical potential range for cathodic protection of X80 steel in soil extract. The results showed that the hydrogen-charged potential was around $-800 \mathrm{mV}$ (vs. SCE), and the applied cathodic potential was of great significance for X80 steel's hydrogen embrittlement. Besides, when the cathodic protection potential was in the range prior to $-850 \mathrm{mV}$, the amount of hydrogen evolution was insignificant, which had a little effect on the mechanical performance of X80 steel. Meanwhile, the fracture morphology showed dimple-like plastic fracture characteristics. On the contrary, with negative shift of the cathodic potential to $-900 \mathrm{mV}$ or more, a plastic brittle transition occurred owing to the large amounts of hydrogen released at this time. Thus, the negative critical potential range of $\mathrm{X} 80$ steel during the cathodic protection process at room temperature in soil extract was determined as $-800 \mathrm{mV} \sim-850 \mathrm{mV}$.

Keywords: API X80 steel, potentialdynamic polarization, EIS, SSRT, hydrogen embrittlement

\section{$\underline{\text { FULL TEXT }}$}

(C) 2020 The Authors. Published by ESG (www.electrochemsci.org). This article is an open access article distributed under the terms and conditions of the Creative Commons Attribution license (http://creativecommons.org/licenses/by/4.0/). 